\title{
Thermal Conductivities of Crosslinked Polyisoprene and Polybutadiene from Molecular Dynamics Simulations
}

\author{
Aleksandr Vasilev*(D, Tommy Lorenz and Cornelia Breitkopf $(\mathbb{D}$ \\ Chair of Technical Thermodynamics, Technische Universität Dresden, 01069 Dresden, Germany; \\ tommy.lorenz@tu-dresden.de (T.L.); cornelia.breitkopf@tu-dresden.de (C.B.) \\ * Correspondence: aleksandr.vasilev@tu-dresden.de
}

Citation: Vasilev, A.; Lorenz, T.; Breitkopf, C. Thermal Conductivities of Crosslinked Polyisoprene and Polybutadiene from Molecular Dynamics Simulations. Polymers 2021, 13, 315. https://doi.org/10.3390/ polym 13030315

Academic Editor: Xiao Hu Received: 18 December 2020 Accepted: 14 January 2021 Published: 20 January 2021

Publisher's Note: MDPI stays neutral with regard to jurisdictional clai$\mathrm{ms}$ in published maps and institutional affiliations.

Copyright: (C) 2021 by the authors. Licensee MDPI, Basel, Switzerland. This article is an open access article distributed under the terms and conditions of the Creative Commons Attribution (CC BY) license (https:// creativecommons.org/licenses/by/ $4.0 /)$.
Abstract: For the first time, the thermal conductivities of vulcanized polybutadiene and polyisoprene have been investigated according to their degree of crosslinking. The C-C and C-S-S-C crosslink bridges, which can be obtained via vulcanization processes using peroxides and sulfur, respectively, are considered. The temperature dependence of the thermal conductivity of soft rubber derived from molecular dynamics (MD) simulations is in very good agreement with the experimental results. The contributions of bonded and non-bonded interactions in the MD simulations and their influence on the thermal conductivities of polyisoprene and polybutadiene are presented. The details are discussed in this paper.

Keywords: molecular dynamics simulations; force field; rubber; polyisoprene; polybutadiene; thermal conductivity

\section{Introduction}

Rubbers are widely used in industry due to their scalable mechanical properties and low masses. Thus, recently, polymers have also served as a basis for interactive fiber-rubber composites consisting of reinforced fibers, shape memory alloys, sensor networks, and magnetic fillers. To predict their thermo-mechanical behavior, experiments and simulations need to be combined. To solve conservation equations with the finite element method (FEM), the thermal properties of each component of the composite as a function of temperature and pressure must be known. These functions can be obtained either from experiments or from theoretical methods, such as molecular dynamics simulations.

Molecular dynamics simulations are a popular tool for investigating the thermal conductivities of polymers [1-9]. A linear dependence of the thermal conductivity on the number of degrees of freedom per repeat unit has been found for polyamide-6,6 [7]. An enhancement of the thermal conductivity of polymers through an increase in molecular weight has been found [2,3], which is in agreement with other theoretical [10,11] and experimental [12,13] data. It has been noticed that, at polymerization degrees above 140, heat transfer is dominated by phonon transport [3]. The influence of the degree of crosslinking on the thermal conductivity of polymers has been investigated [14-17]. For all simulated polymers, the thermal conductivity increases with an increase in the degree of crosslinking. This agrees well with the theory obtained from the network model, where heat conduction through van der Waals and primary bonds is considered [18].

On the other hand, for some polymers, such as polystyrene in Ref. [15] and epoxy resin in Ref. [19], crosslinking does not significantly increase the thermal conductivity. In Ref. [20], it was found that only short crosslink bridges enhance the thermal conductivity. In this case, the crosslinked chains get close to each other; therefore, non-bonded interactions between these chains transfer more heat. It was revealed that with an increase in the degree of crosslinking, the contribution of the non-bonded interactions to the thermal conductivity becomes much higher than the contribution of covalent bonds. This phenomenon has been observed in epoxy resins, where it was revealed that non-bonded interactions are 
dominant in heat transport [19]. If the distance between the crosslinked chains is higher than $2.5 \sigma$ (parameter of the Lennard-Jones potential), then the van der Waals forces are negligible [21].

There are only few research examples in which MD simulations have been used to calculate the thermal conductivities of polybutadiene and polyisoprene, which are widely used as polymer matrixes for rubbers. The thermal conductivities of crosslinked natural rubber with different phr (parts per hundred rubber) of $S$ have been found as functions of temperature [6]. The united atom force field from Ref. [22] was used in this research. The results were compared with experimental data of soft rubber containing $2.5 \mathrm{phr}$ of sulfur and hard rubber containing $47 \mathrm{phr}$ of sulfur [23]. However, these calculated thermal conductivities were roughly two times less than the experimental values. In Ref. [4], the thermal conductivity of untreated natural rubber was calculated. In this research, an adaptive inter-molecular reactive empirical bond order (AIREBO [24]) potential was used to describe the interactions between the atoms, so the hydrogen atoms were modeled explicitly. The results were two times larger than the experimental value.

In Ref. [25], the thermal conductivities of untreated polyisoprene and polybutadiene were found as functions of temperature from MD simulations. The OPLS-UA (United Atom) [26] force field was used to describe the interactions between the atoms. Dihedral and some angle interactions were not considered because the parameters of the united atom force field do not exist for these polymers. It can be concluded that there is a great need for developing accurate force fields for MD simulations of polymers and for more investigations of the nature of heat transport in crosslinked polymers.

Therefore, new modified force fields based on the force fields used in Ref. [25] were developed for MD simulations to find the dependence of the thermal conductivity on the degree of crosslinking for vulcanized polyisoprene and polybutadiene. The results are important for further simulations of elastomers on the macro scale with the finite element method (FEM), in which polyisoprene and polybutadiene are used as polymer matrixes. The findings of this research are also interesting for experimentalists in choosing the type of vulcanization for synthesizing rubbers based on polyisoprene and polybutadiene.

\section{Simulation Details}

The Moltemplate [27] software was used to create cis-1,4-polyisoprene and cis-1,4polybutadiene chains consisting of 200 monomer units for modeling untreated polyisoprene and polybutadiene. For the simulation of vulcanized polyisoprene and polybutadiene molecules, crosslink bridges were prepared with the Moltemplate software as well. Two types of crosslinking bridges were considered: sulfur bridges (C-S-S-C) as in Ref. [6] and C-C bridges as in Ref. [28-30]. Molecules with degrees of crosslinking of 10\%, 20\%, $33 \%, 50 \%, 67 \%$, and $80 \%$ were prepared. In Figure 1a,b, the molecules for modeling vulcanized polybutadiene (C-C bridges) and polyisoprene (C-S-S-C bridges) with a degree of crosslinking of $20 \%$ are shown. The degree of crosslinking (DC) was defined, as in Ref. [15], by equation

$$
\mathrm{DC}=\frac{2 N_{\mathrm{CL}}}{N_{\mathrm{mono}}} \cdot 100 \%,
$$

where $N_{\mathrm{CL}}$ and $N_{\text {mono }}$ denote the total numbers of crosslink bridges and monomer units, respectively. The molecules were randomly distributed in a periodic supercell with the Packmol [31] software (see, as an example, Figure 1c). 


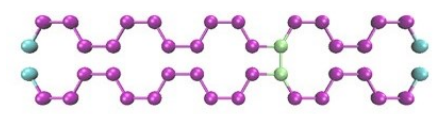

a)

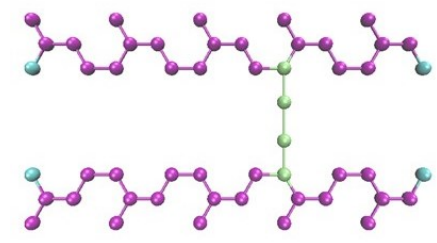

b)

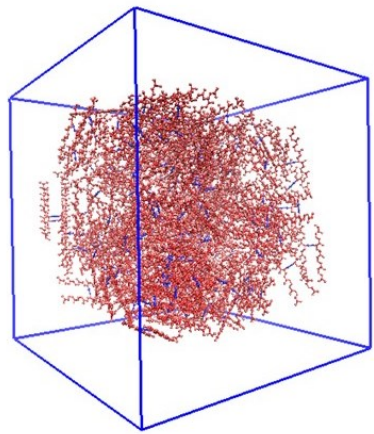

c)

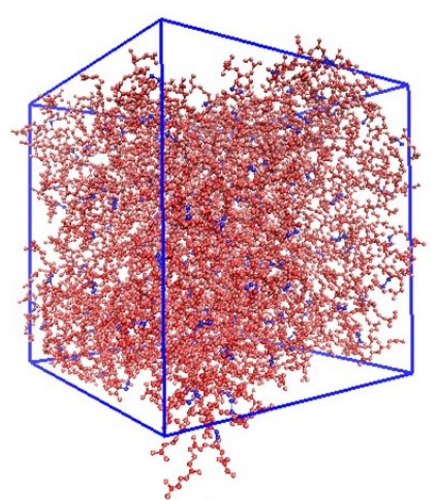

d)

Figure 1. (a) Input structure of a molecule for the MD simulation of polybutadiene crosslinked by C-C bridges with a degree of crosslinking of $20 \%$; (b) input structure of a molecule for MD simulation of polyisoprene crosslinked by C-S-S-C bridges with a degree of crosslinking of $20 \%$; (c) input molecules distributed randomly in the periodic supercell for modeling of polyisoprene vulcanized by sulfur with a degree of crosslinking of $20 \%$; (d) structure of polyisoprene vulcanized by sulfur with a degree of crosslinking of $20 \%$ before calculation of the thermal conductivity.

A united-atom force field was applied to model the polymeric systems. $\mathrm{CH}, \mathrm{CH}_{2}$, and $\mathrm{CH}_{3}$ groups were simulated as "one atom". The total potential energy of a polymeric system is calculated in this approximation as

$$
E=E_{\text {bond }}+E_{\text {angle }}+E_{\text {dihedral }}+E_{\text {non-bonded }} \text {. }
$$

Non-bonded interactions were modeled only with van der Waals interactions. The cutoff distance was set to $10 \AA$ in all simulations. The Lorentz-Berthelot mixing rules were used to find the missing parameters of the Lennard-Jones potential. All simulations were carried out using the LAMMPS [32] software package.

Schematic illustrations of the crosslink bridges and force field parameters used for the MD simulations of polyisoprene and polybutadiene vulcanized by C-S-S-C and C$\mathrm{C}$ bridges are presented in Figure S1 and Tables S1-S4 in the Supplementary Material. Bond stretching and van der Waals interactions were modeled with parameters of the OPLS-UA (United Atom) [26] force field taken from the Moltemplate software. These parameters were used to calculate the thermal conductivities of untreated polyisoprene and polybutadiene [25]. In Ref. [25], however, dihedral and some angle interactions were not considered because parameters of the united atom force field do not exist for these polymers. In the modified force fields used for this research, the parameters for dihedral and angle interactions from the OPLS-AA (All Atom) [26] force field were used to eliminate this problem. The coefficients for special bonds were set to zero in all simulations.

After distribution of the molecules in the periodic supercell, they were polymerized in an NVT ensemble via an algorithm similar to that of Ref. [33]. Each molecule had four $\mathrm{CH}_{3}$ groups in the edges. During this procedure, $\mathrm{CH}_{3}$ groups participating in the creation of a bond between the molecules were turned into $\mathrm{CH}_{2}$ groups. In addition, new bonds, angles, and dihedrals were taken into account for the next time steps of the simulation after creating the new bonds between the molecules. If $M$ is the total number of molecules in the periodic supercell and $N$ is the number of new bonds created between the molecules during the polymerization algorithm, then $x=2 \mathrm{~N} / M$ is the average number of neighbor molecules connected to one molecule. The maximal possible value of $x$ is four. On average, for all simulated systems of vulcanized polyisoprene and polybutadiene, $x$ was equal to 2.22 .

Then, the polymeric systems were heated to a high temperature and were slowly cooled by applying high pressure until normal conditions were reached in an NPT ensemble with a time step of $0.2 \mathrm{fs}$. The procedure of cooling under pressure was performed three times. Nose and Hoover's $[34,35]$ thermostat and barostat with damping parameters of 
100 and 1000 time steps, respectively, were used to reach the desired temperature, pressure, and density of the simulated systems.

Before calculating the thermal conductivity, the polymeric systems were simulated for $100 \mathrm{ps}$ in an NPT ensemble at the desired temperature and atmospheric pressure with a time step of $1 \mathrm{fs}$ to get the equilibrated density and temperature. After that, the systems were modeled in an NVE ensemble for 900 ps with a time step of $1 \mathrm{fs}$. During this procedure, at each time step, the total heat flux was calculated. By using the Green-Kubo formula, the thermal conductivity of an isotropic material can be found as

$$
\lambda=\frac{V}{3 k_{\mathrm{B}} T^{2}} \int_{0}^{\infty}<\vec{J}(0) \vec{J}(t)>\mathrm{d} t,
$$

where $\vec{J}$ is the heat flux calculated with the following equation taken from Ref. [36]:

$$
\vec{J}=\frac{1}{V}\left[\sum_{i} e_{i} \vec{v}-\sum_{i} S_{i} \vec{v}\right],
$$

where $e_{i}$ is the total energy of the $i$-th atom. The first term is the convectional part of the total heat flux, which represents the heat flux due to the movement of atoms in the system. $S_{i}$ is the per-atom stress tensor calculated with the equation [37]:

$$
S_{a b}=-m v_{a} v_{b}-W_{a b},
$$

where $a$ and $b$ take on the values $x, y$, and $z$, and $W_{a b}$ is the virial contribution, calculated as [37]:

$$
W_{a b}=\sum_{n=1}^{N_{p}} r_{I 0_{a}} F_{I_{b}}+\sum_{n=1}^{N_{b}} r_{I 0_{a}} F_{I_{b}}+\sum_{n=1}^{N_{a}} r_{I 0_{a}} F_{I_{b}}+\sum_{n=1}^{N_{d}} r_{I 0_{a}} F_{I_{b}}+\sum_{n=1}^{N_{i}} r_{I 0_{a}} F_{I_{b}}
$$

where $N_{p}$ is the number of neighbors of atom $I$ that act on atom $I$ via van der Waals interaction, and $N_{b}, N_{a}, N_{d}$, and $N_{i}$ are the numbers of bonds, angles, dihedrals, and impropers, respectively, and the atom $I$ is included in these interactions. $F_{I}$ is the force acting on atom $I$ due to these interactions, and $r_{I 0}$ is the relative position of the atom $I$ with respect to the geometric center of the interacting atoms.

Due to the discretization of time in MD simulations, Equation (4) can be written as follows [38]:

$$
\lambda\left(\tau_{M}\right)=\frac{V \Delta t}{3 k_{\mathrm{B}} T^{2}} \sum_{m=1}^{M} \frac{1}{(N-m)} \sum_{n=1}^{N-m} J_{i}(n) J_{j}(m+n),
$$

where $\lambda\left(\tau_{M}\right)$ is the thermal conductivity obtained from summation to time step $M(M=0$, $1, \ldots, N-1), N$ is the total number of simulation steps, and $\tau_{M}=M \Delta t$.

Models of untreated polyisoprene and polybutadiene with 12,000, 24,000, and 48,000 atoms were prepared and tested to find an optimal size of the periodic supercell for MD simulations of vulcanized polyisoprene and polybutadiene. In the case of untreated polyisoprene, the thermal conductivities for the systems with 12,000, 24,000, and 48,000 atoms were $0.15,0.149$, and $0.154 \mathrm{~W} / \mathrm{m} / \mathrm{K}$, respectively. For untreated polybutadiene, the thermal conductivities of the systems with 12,000, 24,000, and 48,000 atoms were 0.209, 0.204 , and $0.213 \mathrm{~W} / \mathrm{m} / \mathrm{K}$, respectively. Consequently, the systems with 12,000 atoms were used for MD simulations of vulcanized polyisoprene and polybutadiene.

\section{Results and Discussion}

The thermal conductivities of crosslinked polybutadiene and polyisoprene with a degree of crosslinking of $20 \%$ are presented in Figure $2 \mathrm{a}$. The data for the analysis were taken from the last correlation time interval. As shown in Figure 2a, a correlation length of 1.5 ps was sufficient for convergence of the thermal conductivities. The thermal conductivities 
along each direction were compared. It was observed that they were equal in all directions. Thus, the models of the crosslinked polymers in the MD simulations were isotropic.

Using the one-dimensional harmonic oscillator model [6], the mechanism of heat transfer was derived. The first minima of the normalized heat flux autocorrelation functions of the vulcanized polyisoprene and polybutadiene with a degree of crosslinking of $20 \%$ are presented in Figure $2 \mathrm{~b}$. For the crosslinked polyisoprene, the first minimum (see Figure $2 \mathrm{~b}$ ) of the normalized heat flux autocorrelation function is located at $t \approx 16 \mathrm{fs}$, which corresponds to a wavenumber of $\bar{v} \approx 332 \mathrm{~cm}^{-1}$. This is close to the wavenumber of C-C-C deformation vibrations in cis-1,4-polyisoprene $\left(\bar{v}=390 \mathrm{~cm}^{-1}\right)$ [39]. For vulcanized polybutadiene, the first minimum (see Figure $2 \mathrm{~b}$ ) of the normalized heat flux autocorrelation function is located at $t \approx 14 \mathrm{fs}$ and matches a wavenumber of $\bar{v} \approx 379 \mathrm{~cm}^{-1}$, which is close to the wavenumbers of the C-C-C deformation vibrations of cis-1,4-polybutadiene $\left(\bar{v} \approx 405 \mathrm{~cm}^{-1}\right)$ and trans-1,4-polybutadiene $\left(\bar{v} \approx 439 \mathrm{~cm}^{-1}\right)$ [40]. As a result, the heat in crosslinked polyisoprene and polybutadiene is mainly transferred by low-frequency phonons, which correspond to low-energy C-C-C deformation vibrations. This is in agreement with Ref. [3].

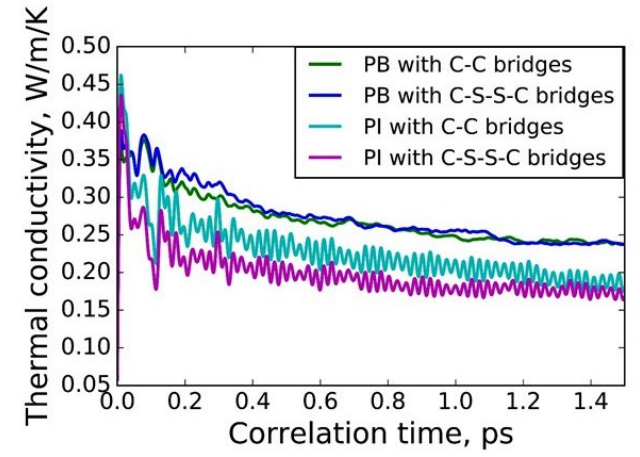

a)

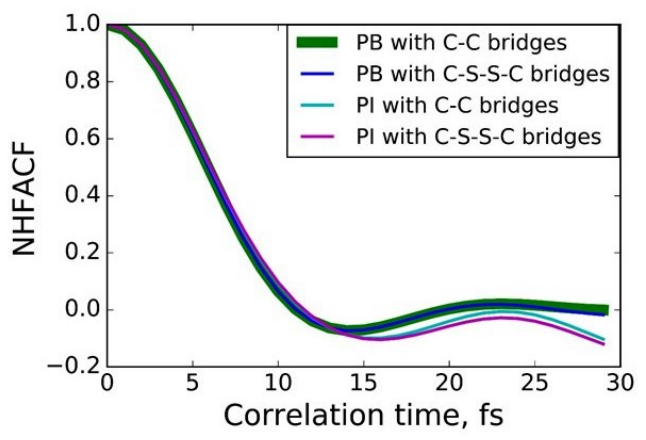

b)

Figure 2. (a) Thermal conductivities of polybutadiene crosslinked by C-C bridges (green line) and by C-S-S-C bridges (blue line) and polyisoprene vulcanized by C-C bridges (cyan line) and by C-S-S-C bridges (magenta line) at normal conditions as a function of correlation time; (b) the first minima of the normalized heat flux autocorrelation functions (NHFACFs) of polybutadiene crosslinked by C-C bridges (green line) and by C-S-S-C bridges (blue line) and polyisoprene vulcanized by C-C bridges (cyan line) and by C-S-S-C bridges (magenta line) at normal conditions.

The results for the thermal conductivities of vulcanized polyisoprene and polybutadiene depending on the degree of crosslinking are presented in Figure 3. For crosslinked polyisoprene with a degree of crosslinking below $33 \%$, a constant thermal conductivity with small fluctuations was observed (as an example, see Figure 3a). Data points from the last $0.1 \mathrm{ps}$ of the last correlation time interval were taken for the calculation of the converged values of the thermal conductivities of the models of crosslinked polyisoprene.

The thermal conductivities of polyisoprene and polybutadiene increased with the increase in the degree of crosslinking, which agrees well with similar research on polyethylene [14,15], polystyrene [15], phenolic resins [16,17], and the network model [18]. Typically, polymers are inhomogeneous at high degrees of crosslinking. For example, there are hyper-crosslinked networks of polystyrene [41], polysulfones [42], polyarylates [42], poly(vinylpyridines) [43], and polyanilines [44]. However, analysis of the thermal conductivity tensors shows that in all of our simulated systems, the thermal conductivity was uniform in all directions. Moreover, the thermal conductivities of polybutadiene and polyisoprene increase slightly more at crosslinking degrees higher than $67 \%$ than at lower degrees of crosslinking. Visual changes in the simulated structures other than the number of crosslinking bridges were not observed with further crosslinking up to a crosslinking degree of $80 \%$. The concrete type of the crosslinking bridge did not significantly influence the thermal conductivity of polyisoprene and polybutadiene. For polybutadiene, the 
crosslinking by C-C bridges enhanced the thermal conductivity slightly more compared to C-S-S-C bridges. These results are close to those in the literature on polybutadiene rubber $(\lambda=0.23 \mathrm{~W} / \mathrm{m} / \mathrm{K}[45])$. The results for vulcanized polyisoprene are also close to those in the literature $(\lambda=0.14 \mathrm{~W} / \mathrm{m} / \mathrm{K}$ [45], $\lambda \approx 0.15 \mathrm{~W} / \mathrm{m} / \mathrm{K}$ (soft rubber) [23], and $\lambda \approx 0.16 \mathrm{~W} / \mathrm{m} / \mathrm{K}$ (hard rubber) [23]).

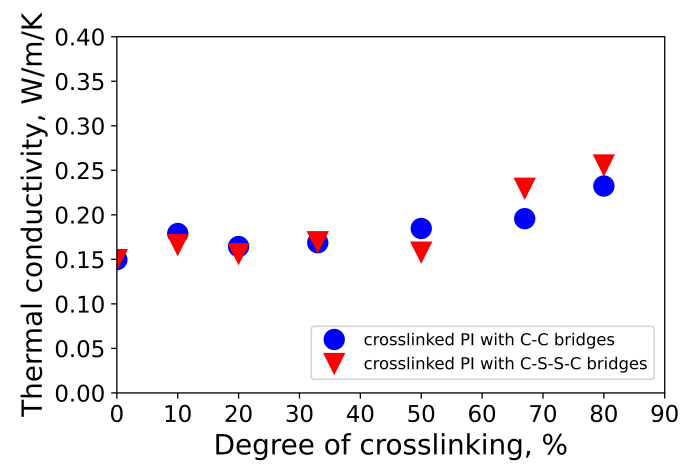

(a)

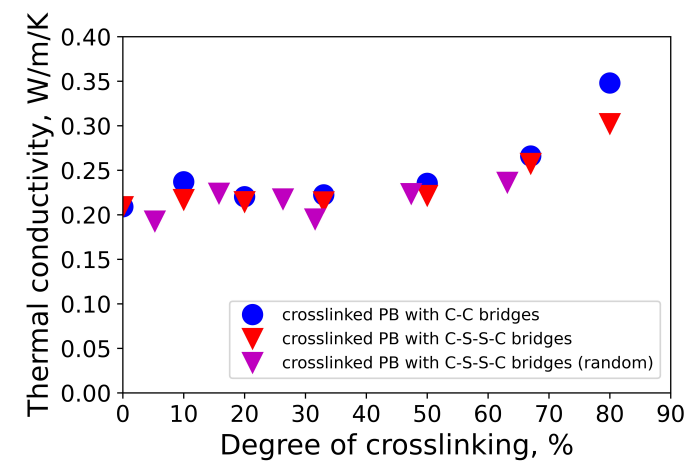

(b)

Figure 3. (a) Dependency of the thermal conductivity of crosslinked polyisoprene: red triangles and blue circles correspond to structures of vulcanized polyisoprene with C-S-S-C and C-C bridges, respectively; (b) dependency of thermal conductivity of crosslinked polybutadiene: red triangles and blue circles correspond to structures of vulcanized polybutadiene with C-S-S-C and C-C bridges, respectively; magenta triangles correspond to models of vulcanized polybutadiene with randomly distributed C-S-S-C bridges.

The thermal conductivity of untreated polyisoprene $(\lambda=0.15 \mathrm{~W} / \mathrm{m} / \mathrm{K})$ calculated at normal conditions via the modified force field is in a good agreement with the experimental data $(0.134 \mathrm{~W} / \mathrm{m} / \mathrm{K}$ [46], $0.14 \mathrm{~W} / \mathrm{m} / \mathrm{K}$ [25], and $0.145 \mathrm{~W} / \mathrm{m} / \mathrm{K}$ [47]). The result for untreated polybutadiene $(\lambda=0.21 \mathrm{~W} / \mathrm{m} / \mathrm{K})$ with the modified force field is close to the experimental data $(0.174 \mathrm{~W} / \mathrm{m} / \mathrm{K}$ [25], and $0.19 \mathrm{~W} / \mathrm{m} / \mathrm{K}$ [48]).

In Figure $3 b$, the dependence of thermal conductivity on the degree of crosslinking for vulcanized polybutadiene with randomly distributed C-S-S-C crosslink bridges is presented. The modeled vulcanized polybutadiene consists of 16 chains composed of 190 monomer units connected by randomly distributed C-S-S-C crosslinking bridges. It is obvious in Figure 3 that the type of distribution (random or uniform) of the crosslinking bridges does not significantly influence the final thermal conductivity. Due to that, only models of vulcanized polybutadiene and polyisoprene with uniformly distributed crosslinking bridges were considered in this research.

To understand the microscopic picture of heat transfer in vulcanized polybutadiene and polyisoprene, the contributions of bonded and non-bonded interactions and translational motion (convection) to the thermal conductivity were investigated. These contributions to the thermal conductivities of the modeled untreated and crosslinked polymers are shown in Figure 4a. With an increase in the degree of crosslinking, the contributions of bonded and non-bonded interactions to the thermal conductivity increase. The same was observed for crosslinked polyethylene [15].

The thermal conductivity of polyisoprene crosslinked with C-S-S-C bridges (degree of crosslinking is $5.3 \%$, which corresponds to $2.5 \mathrm{phr}$ (parts per hundred rubber) of sulfur) as a function of the temperature at atmospheric pressure is shown in Figure $4 \mathrm{~b}$. The results agree very well with the experimental data from Ref. [23]. Thus, MD simulations performed with the force fields used in that paper can provide the thermal conductivities of soft rubbers as a function of temperature and degree of crosslinking for macroscale simulations with FEM. 


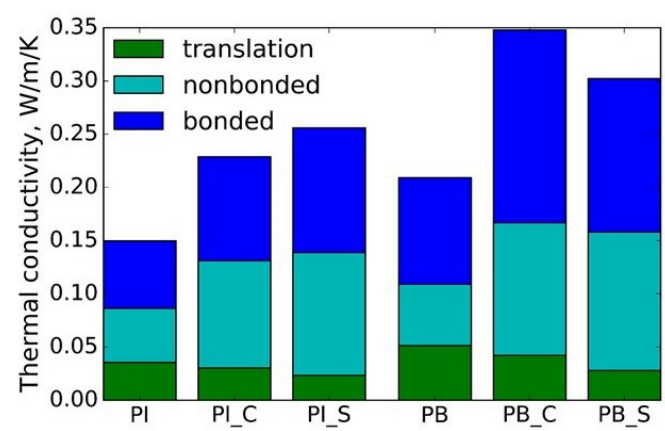

a)

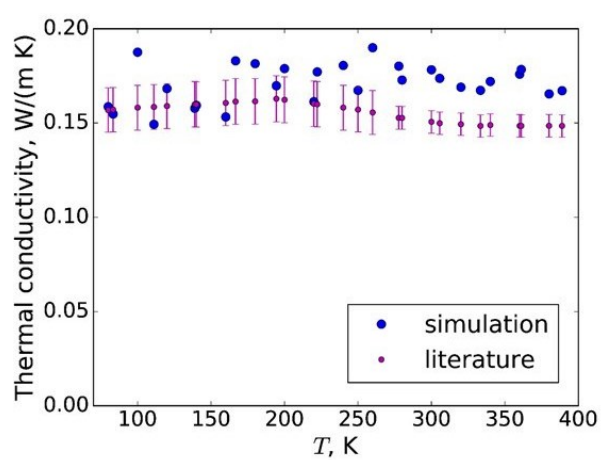

b)

Figure 4. (a) Compositions of thermal conductivities of untreated polyisoprene (PI), vulcanized polyisoprene with C-C bridges (PI_C) with a degree of crosslinking of $80 \%$, vulcanized polyisoprene with C-S-S-C bridges (PI_S) with degree of crosslinking $80 \%$, untreated polybutadiene (PB), vulcanized polybutadiene with C-C bridges (PB_C) with a degree of crosslinking of $80 \%$, and vulcanized polybutadiene with C-S-S-C bridges (PB_S) with a degree of crosslinking of $80 \%$; (b) dependence of the thermal conductivity of polyisoprene crosslinked with C-S-S-C bridges (degree of crosslinking is $5.3 \%$, which corresponds to $2.5 \mathrm{phr}$ (parts per hundred rubber) of sulfur) on temperature at atmospheric pressure. For comparison, data from the literature on soft rubber from Ref. [23] are shown.

\section{Conclusions}

New modified force fields for MD simulations of polyisoprene and polybutadiene, which treat all many-body interactions, have been developed. For the first time, the thermal conductivities of polybutadiene and polyisoprene crosslinked by C-S-S-C and C-C bridges were theoretically investigated as a function of the degree of crosslinking. The dependences of the polymers' thermal conductivities on the degree of crosslinking are in agreement with MD simulations performed for other polymeric systems. The type of crosslinking bridge studied here has no significant influence on the heat transfer in vulcanized polyisoprene and polybutadiene. The calculated values of the thermal conductivities of untreated and vulcanized systems of polybutadiene and polyisoprene agree very well with the experimental data, and the dependence of the thermal conductivity of soft rubber on temperature is close to the experimental data, too. From the analysis of the normalized heat flux autocorrelation functions of the polymers, it was found that the main mechanism of heat transfer in these polymers is through transport of low-frequency phonons, which has already been observed for other polymers. MD simulations of the modified force fields via the Green-Kubo approach can be used to obtain the thermal conductivities of crosslinked polyisoprene and polybutadiene for macroscale simulations with FEM rubbers based on these polymers.

Supplementary Materials: The following are available online at https:/ / www.mdpi.com/2073-4 360/13/3/315/s1, Figure S1: (a) C-C bridge between cis-1,4-polybutadiene chains; (b) C-C bridge between cis-1,4-polyisoprene chains; (c) C-S-S-C between cis-1,4-polyisoprene chains; (d) C-S-S-C bridge between cis-1,4-polybutadiene chains, Table S1: Force field parameters for MD simulation of vulcanized polyisoprene with C-S-S-C crosslink bridges, Table S2: Force field parameters for MD simulation of vulcanized polybutadiene with C-S-S-C crosslink bridges, Table S3: Force field parameters for MD simulation of vulcanized polyisoprene with C-C crosslink bridges, Table S4: Force field parameters for MD simulation of vulcanized polybutadiene with C-C crosslink bridges.

Author Contributions: Conceptualization, A.V.; data curation, A.V.; formal analysis, A.V.; investigation, A.V.; methodology, A.V.; project administration, C.B.; software, A.V.; supervision, T.L. and C.B.; validation, A.V.; visualization, A.V.; writing-original draft, A.V.; writing-review and editing, T.L. and C.B. All authors have read and agreed to the published version of the manuscript. 
Funding: The DFG research project 380321452/GRK2430 was supported by the Deutsche Forschungsgemeinschaft (DFG, German Research Foundation). The financial support is gratefully acknowledged.

Institutional Review Board Statement: Not applicable.

Informed Consent Statement: Not applicable.

Data Availability Statement: Not applicable.

Acknowledgments: The computational time and support by the Zentrum für Informationsdienste und Hochleistungsrechnen $(\mathrm{ZIH})$ in Dresden are highly appreciated (project p_thermo_dat).

Conflicts of Interest: The authors declare no conflict of interest.

\section{References}

1. Rossinsky, E.; Müller-Plathe, F. Anisotropy of the thermal conductivity in a crystalline polymer: Reverse nonequilibrium molecular dynamics simulation of the $\delta$ phase of syndiotactic polystyrene. J. Chem. Phys. 2009, 130, 134905. [CrossRef] [PubMed]

2. Liu, J.; Yang, R. Tuning the thermal conductivity of polymers with mechanical strains. Phys. Rev. B 2010, 81, 174122. [CrossRef]

3. Zhao, J.; Jiang, J.W.; Wei, N.; Zhang, Y.; Rabczuk, T. Thermal conductivity dependence on chain length in amorphous polymers. J. Appl. Phys. 2013, 113, 184304. [CrossRef]

4. He, Y.; Lian-Xiang, M.; Tang, Y.Z.; Wang, Z.P.; Li, W.; Kukulka, D. Thermal Conductivity of Natural Rubber Using Molecular Dynamics Simulation. J. Nanosci. Nanotechnol. 2015, 15, 3244-3248. [CrossRef] [PubMed]

5. Li, S.; Yu, X.; Bao, H.; Yang, N. High Thermal Conductivity of Bulk Epoxy Resin by Bottom-Up Parallel-Linking and Strain: A Molecular Dynamics Study. J. Phys. Chem. C 2018, 122, 13140-13147. [CrossRef]

6. Engelmann, S.; Meyer, J.; Hentschke, R. Computer simulation of thermal conductivity in vulcanized polyisoprene at variable strain and temperature. Phys. Rev. B 2017, 96, 054110. [CrossRef]

7. Lussetti, E.; Terao, T.; Müller-Plathe, F. Nonequilibrium molecular dynamics calculation of the thermal conductivity of amorphous polyamide-6, 6. J. Phys. Chem. B 2007, 111, 11516-11523. [CrossRef] [PubMed]

8. Algaer, E. Thermal Conductivity of Polymer Materials—Reverse Nonequilibrium Molecular Dynamics Simulations. Ph.D. Thesis, Technische Universität, Darmstadt, Germany, 2010.

9. Terao, T.; Lussetti, E.; Müller-Plathe, F. Nonequilibrium molecular dynamics methods for computing the thermal conductivity: Application to amorphous polymers. Phys. Rev. E 2007, 75, 057701. [CrossRef]

10. Ueberreiter, K.; Otto-Laupenmühlen, E. Spezifische Wärme, spezifisches Volumen, Temperatur-und Wärmeleitfähigkeit von Hochpolymeren. Z. Naturforschung A 1953, 8, 664-673. [CrossRef]

11. Hansen, D.; Kantayya, R.; Ho, C. Thermal conductivity of high polymers-the influence of molecular weight. Polym. Eng. Sci. 1966, 6, 260-262. [CrossRef]

12. Hansen, D.; Ho, C.C. Thermal conductivity of high polymers. J. Polym. Sci. Part A Gen. Pap. 1965, 3, 659-670. [CrossRef]

13. Anderson, D. Thermal conductivity of polymers. Chem. Rev. 1966, 66, 677-690. [CrossRef]

14. Xiong, X.; Yang, M.; Liu, C.; Li, X.; Tang, D. Thermal conductivity of cross-linked polyethylene from molecular dynamics simulation. J. Appl. Phys. 2017, 122, 035104. [CrossRef]

15. Kikugawa, G.; Desai, T.G.; Keblinski, P.; Ohara, T. Effect of crosslink formation on heat conduction in amorphous polymers. J. Appl. Phys. 2013, 114, 034302. [CrossRef]

16. Monk, J.D.; Bucholz, E.W.; Boghozian, T.; Deshpande, S.; Schieber, J.; Bauschlicher, C.W., Jr.; Lawson, J.W. Computational and experimental study of phenolic resins: Thermal-mechanical properties and the role of hydrogen bonding. Macromolecules 2015, 48, 7670-7680. [CrossRef]

17. Monk, J.D.; Haskins, J.B.; Bauschlicher, C.W., Jr.; Lawson, J.W. Molecular dynamics simulations of phenolic resin: Construction of atomistic models. Polymer 2015, 62, 39-49. [CrossRef]

18. Yamamoto, O. Thermal conductivity of cross-linked polymers. Polym. J. 1971, 2, 509-517. [CrossRef]

19. Huo, R.; Zhang, Z.; Athir, N.; Fan, Y.; Liu, J.; Shi, L. Designing high thermal conductivity of cross-linked epoxy resin via Molecular Dynamics Simulation. Phys. Chem. Chem. Phys. 2020, 22, 19735-19745. [CrossRef]

20. Rashidi, V.; Coyle, E.J.; Sebeck, K.; Kieffer, J.; Pipe, K.P. Thermal conductance in cross-linked polymers: Effects of non-bonding interactions. J. Phys. Chem. B 2017, 121, 4600-4609. [CrossRef]

21. Toxvaerd, S.; Dyre, J.C. Communication: Shifted forces in molecular dynamics. J. Chem. Phys. 2011, 134, 081102. [CrossRef]

22. Harmandaris, V.; Doxastakis, M.; Mavrantzas, V.; Theodorou, D. Detailed molecular dynamics simulation of the self-diffusion of n-alkane and cis-1, 4 polyisoprene oligomer melts. J. Chem. Phys. 2002, 116, 436-446. [CrossRef]

23. Carwile, L.C.; Hoge, H.J. Thermal Conductivity of Soft Vulcanized Natural Rubber: Selected Values. R. Chem. Tech. 1966, 39, 126-131. [CrossRef]

24. Stuart, S.J.; Tutein, A.B.; Harrison, J.A. A reactive potential for hydrocarbons with intermolecular interactions. J. Chem. Phys. 2000, 112, 6472-6486. [CrossRef] 
25. Vasilev, A.; Lorenz, T.; Breitkopf, C. Thermal Conductivity of Polyisoprene and Polybutadiene from Molecular Dynamics Simulations and Transient Measurements. Polymers 2020, 12, 1081. [CrossRef] [PubMed]

26. Jorgensen, W. OPLS All-Atom Parameters for Organic Molecules, Ions, Peptides E Nucleic Acids; Yale University: New Haven, CT, USA, 2009.

27. Jewett, A.I.; Zhuang, Z.; Shea, J.E. Moltemplate a coarse-grained model assembly tool. Biophys. J. 2013, 104, 169a. [CrossRef]

28. Kruželák, J.; Sỳkora, R.; Hudec, I. Vulcanization of rubber compounds with peroxide curing systems. Rubber Chem. Technol. 2017, 90, 60-88. [CrossRef]

29. Kvasničáková, A.; Kruželák, J.; Medlenová, E.; Dosoudil, R.; Hudec, I.; Gořalík, M. Rubber magnets cured with peroxide and coagents. J. Elastomers Plast. 2020, 52, 253-270. [CrossRef]

30. Kruželák, J.; Sỳkora, R.; Dosoudil, R.; Hudec, I. Relationship between the cross-link structure and properties of peroxide and sulfur-cured magnetic composites based on NR and NBR. J. Elastomers Plast. 2017, 49, 459-480. [CrossRef]

31. Martínez, L.; Andrade, R.; Birgin, E.G.; Martínez, J.M. PACKMOL: A package for building initial configurations for molecular dynamics simulations. J. Comput. Chem. 2009, 30, 2157-2164. [CrossRef]

32. Plimpton, S. Fast parallel algorithms for short-range molecular dynamics. J. Comput. Phys. 1995, 117, 1-19. [CrossRef]

33. Hager, J.; Hentschke, R.; Hojdis, N.W.; Karimi-Varzaneh, H.A. Computer simulation of particle-particle interaction in a model polymer nanocomposite. Macromolecules 2015, 48, 9039-9049. [CrossRef]

34. Nosé, S. A molecular dynamics method for simulations in the canonical ensemble. Mol. Phys. 1984, 52, 255-268. [CrossRef]

35. Hoover, W.G. Canonical dynamics: Equilibrium phase-space distributions. Phys. Rev. A 1985, 31, 1695. [CrossRef] [PubMed]

36. Compute Heat/Flux Command. Available online: https://lammps.sandia.gov/doc/compute_heat_flux.html (accessed on 18 January 2021).

37. Compute Centroid/Stress/Atom Command. Available online: https://lammps.sandia.gov/doc/compute_stress_atom.html (accessed on 18 January 2021).

38. Schelling, P.K.; Phillpot, S.R.; Keblinski, P. Comparison of atomic-level simulation methods for computing thermal conductivity. Phys. Rev. B 2002, 65, 144306. [CrossRef]

39. Nallasamy, P.; Mohan, S. Vibrational spectra of cis-1, 4-polyisoprene. Arab. J. Sci. Eng. 2004, $29,17-26$.

40. Nallasamy, P.; Anbarasan, P.; Mohan, S. Vibrational spectra and assignments of cis- and trans-1,4-polybutadiene. Turk. J. Chem. 2002, 26, 105-112.

41. Tsyurupa, M.; Davankov, V. Porous structure of hypercrosslinked polystyrene: State-of-the-art mini-review. React. Funct. Polym. 2006, 66, 768-779. [CrossRef]

42. Tsyurupa, M.; Davankov, V. Hypercrosslinked polymers: Basic principle of preparing the new class of polymeric materials. React. Funct. Polym. 2002, 53, 193-203. [CrossRef]

43. Pavlova, L.; Pavlov, M.; Davankov, V. The First Representatives of Hypercrosslinked Hydrophilic Networks: Alkylation and Polymerization of 4-Vinylpyridine in an Ionic Liquid. In Doklady Chemistry; Springer: Berlin/Heidelberg, Germany, 2006; Volume 406, pp. 6-8.

44. Germain, J.; Fréchet, J.M.; Svec, F. Hypercrosslinked polyanilines with nanoporous structure and high surface area: Potential adsorbents for hydrogen storage. J. Mater. Chem. 2007, 17, 4989-4997. [CrossRef]

45. Gent, A.N.; Sueyasu, T.; Wang, C. Tables of physical constants. In Engineering with Rubber; Elsevier: Amsterdam, The Netherlands, 2012; pp. 423-433.

46. Wood, L. Polymer Handbook; Brandrup, J., Immergut, E.H., Eds.; Wiley: New York, NY, USA, 1975 ; Volume 7.

47. Tonpheng, B.; Andersson, O. Crosslinking, thermal properties and relaxation behaviour of polyisoprene under high-pressure. Eur. Polym. J. 2008, 44, 2865-2873. [CrossRef]

48. Tonpheng, B.; Yu, J.; Andersson, O. Effects of cross-links, pressure and temperature on the thermal properties and glass transition behaviour of polybutadiene. Phys. Chem. Chem. Phys. 2011, 13, 15047-15054. [CrossRef] [PubMed] 